\title{
Editorial
}

\section{Carta al Consejo Nacional e Internacional de colaboradores de la revista Cultura de Paz}

Por Denis Torres ${ }^{1}$

Estimados amigos:

Queremos ante todo, reiterar nuestras sinceras muestras de gratitud y reconocimiento por habernos acompañado como miembros del Consejo Nacional e Internacional de Colaboradores de la revista Cultura de Paz, a lo largo de 24 años. Sin su pensamiento y compromiso este proyecto editorial, académico y científico hubiera sido imposible. Pocas veces en nuestro país hemos asistido a un esfuerzo de esta naturaleza, sostenido e ininterrumpido durante un cuarto de siglo.

Es la única revista en América Latina y talvez en el mundo, que lleva ese nombre y desde su origen se planteó promover, diseminar ese paradigma, que fuera un espacio donde concurre la diversidad de pensamientos, tolerante, como lo hemos querido para nuestra sociedad. Esfuerzos editoriales, incluso con patrocinio, no han llegado tan lejos. De ahí que la revista Cultura de Paz sea una de las publicaciones de mayor vida y vigencia de la cultura nacional.

Recordamos en el primer número la colaboración del Padre Xabier Gorostiaga: "La Copa de Champagne", una de las primeras críticas al neoliberalismo en los noventa; en el segundo, el trabajo del arqueólogo y antropólogo, Dr. Frederick Lange: "2000 años de paz precolombina", que muestra un extenso período de paz, 750 años antes de la conquista y descubre la existencia de un régimen social donde la mujer tenía preeminencia en Nicaragua.

Así, la revista fue incorporando parte relevante del pensamiento nacional, latinoamericano y mundial, abordando la temática amplia de la Cultura de Paz en un tiempo y lugar áridos en términos de producción de pensamiento y debate de ideas, en un tiempo de crisis posbélica y de derrota de paradigmas.

Cómo no valorar las contribuciones de filosofía política, plenamente vigentes, de Alejandro Serrano Caldera; sobre el desarrollo de la educación superior de Carlos Tünnermann Bernheim; de economía política, por Jaime Wheelock Román; reflexiones sobre temas sociológicos, ideológicos y culturales "en busca de la revolución perdida" de Orlando Núñez; aportes relativos a la educación para la paz por Juan Bautista Arrien; cultura y desarrollo de Francisco Lacayo Parajón; Pablo Antonio Cuadra, compartiendo su entrevista al Dalai Lama; los trabajos sobre epistemología de la cultura de paz, de Anastasio Lovo; la perspectiva teológica de la cultura de paz, del teólogo ecuménico José Miguel Torres; sobre los derechos humanos y la educación en valores de Erwin Silva y sobre la cultura política nicaragüense de Emilio Álvarez Montalván; Miguel de Castilla con sus reflexiones sobre la cultura de paz en Nicaragua; Germán Romero aportando contribuciones de gran calado sobre la violencia en la historia de nuestro país.

Así también a escritores como Sergio Ramírez y Ernesto Cardenal, quienes generosamente nos brindaron textos inéditos de sus novelas y poesía, respectivamente. Artistas como Omar d' León con su pintura y sus frecuentes ilustraciones y en él, a todos los pintores y pintoras de Nicaragua, desde la generación de Armando Morales, Fernando Saravia y Rossi López; la de Orlando Sobalvarro y Leoncio Sáenz; la de Róger Pérez de la Rocha e Ilse Ortiz de Manzanares; la de Raúl Marín, Sergio Velásquez, Denis Núñez y Claudia Rocha, la de Winston Miranda, Bygocha y David Salvador, hasta la de Damiana Corea, que han engalanado nuestras portadas y a través de ellos, se ha enaltecido el arte nicaragüense.

1 Director del Instituto Martin Luther King- UPOLI. 
Aprovecho también para traer a la memoria, cómo personalidades mundiales, académicos y especialistas de distintas disciplinas respondieron $\sin$ condiciones a nuestra solicitud de integrar el Consejo Internacional de Colabores. Cabe mencionar al filósofo latinoamericano Don Leopoldo Zea; al teórico de la paz y el desarrollo Johan Galtung; Federico Mayor, que universalizara la cultura de paz desde la UNESCO; los pintores Maurizio Governatori, José Luis Cuevas y Vlady; Carmen Magallón, académica, pacifista y feminista; Nydia Castillo, académica, especialista en desarrollo humano; Elena Poniatowska, escritora, Premio Cervantes; la filósofa Celia Amorós; Marcela Lagarde, feminista latinoamericana; Alicia Cabezudo, educadora latinoamericana; Roberto Cuéllar, promotor de los derechos humanos desde diferentes organismos institucionales especializados; John Paul Lederach, especialista mundial en gestión pacífica de conflictos; Santiago Genovés, Padre del Manifiesto de Sevilla; Edelberto Torres y Pablo González Casanova, eminentes sociólogos latinoamericanos; Hartmut Quehl, Presidente del Consejo Internacional de Investigaciones sobre la Violencia; entre otros.

Ahora la revista Cultura de Paz, además de su edición impresa, está integrada a 5 directorios internacionales en línea, destacándose como una de las 5 mejores revistas científicas del país, de las 201 revistas alojadas en LATINDEX; y compartiendo con ellas, desde el 2010 a la fecha, más de 600 mil descargas de sus artículos a nivel mundial. En el 2013 fue premiada por la Vicepresidencia de la República por su relevante labor en visibilizar la producción científica de Nicaragua. El desarrollo de su calidad la potencia para incorporarse a nuevos espacios internacionales.

Recibimos comunicaciones de investigadores, profesores visitantes internacionales que nos manifiestan que en ella encuentran un apoyo valioso en su labor académica. Fruto de la calidad de su contenido, de la permanencia y vigencia de muchos artículos sobre áreas como: género, derechos humanos, teoría de la paz, gestión de conflictos, juventud, poblaciones originarias, entre otros, se está organizando un primer libro sobre selección de su articulado, en este caso, sobre Género y Cultura de Paz, y se pretende hacer lo mismo con su sección literaria, en la cual publicamos poesía, cuento corto y pintura, como ejes de nuestra identidad cultural.
Hace apenas unos días, Editorial Española solicitó, a partir de la publicación del artículo "Cultura de paz, integración latinoamericana y universidades", del profesor Erwin Silva, su ampliación para ser parte de un libro de este organismo sobre la temática. Así, la revista también pasará a ser fuente de contenidos para libros de texto en apoyo a la labor académica y científica.

Estimados amigos, las páginas de Cultura de Paz se mantienen abiertas a ustedes. La cultura de paz ya no es un concepto desconocido en el mundo, las Naciones Unidas le dedicaron un Decenio (2001-2010), con su Programa y Plan de Acción; en la Segunda Declaración de La Habana de la CELAC, América Latina acogió plenamente los postulados de la cultura de paz, y la región fue declarada Zona de Paz, comprometiéndose cada país a abstenerse del uso de armas para dirimir los conflictos entre sus países miembros.

Estamos formulando una iniciativa para que la CELAC marque un nuevo paso en esta dirección, concertando una Declaración que llame a los países de América Latina y El Caribe, a elevar la cultura de paz a rango constitucional, estableciéndola como fundamento de sus sistemas educativos; nuestro Instituto promovió que la Asamblea General de Naciones Unidas, declarara el 2009, como Año Internacional de la Reconciliación y en actualidad, estamos promoviendo que se introduzca en la Asamblea General de la ONU, una resolución que declare para siempre, un Día Internacional de la Reconciliación, así como hay uno para la Mujer, el Medioambiente, los Derechos Humanos, entre otros, que fije la atención de la humanidad sobre este paradigma crucial; la educación para la paz sigue siendo uno de los instrumentos fundamentales para prevenir la guerra y construir la paz.

Ante la partida de varios miembros de los consejos de colaboradores, estamos invitando a intelectuales, académicos y especialistas de nuevas generaciones para que se sumen y den sostenibilidad a este esfuerzo colectivo que representa Cultura de Paz, estamos seguros que el compromiso de ustedes, llevará también a su propio compromiso. Si ustedes tienen a bien recomendar posibles miembros de los Consejos Nacionales e Internacionales para la revista, serán bienvenidos, ello redundará en su fortalecimiento y continuidad. 